\title{
PATRIMONIO TURÍSTICO E IDENTIDAD CULTU- RAL. EL PATRIMONIO DE LA HUMANIDAD
}

\author{
Joaquín BOSQUE SENDRA Error. El autor es: Joaquín Bosque Maurel \\ Catedrático Em. de Geografía Humana. Univ. Complutense de Madrid.
}

Las actividades relacionadas con el ocio y el turismo constituyen hoy uno de los negocios más importantes y atractivos en la vida económica universal. Y constituyen una atracción en gran medida dependiente de la diversidad y calidad de los numerosos productos que se ofrecen al presunto consumidor, en teoría el conjunto de la población de la Tierra. Pero todo ello dentro de unos cambios en el tiempo y en el espacio a los que es muy sensible la demanda, cada vez más exigente. Así, en el desarrollo reciente del turismo y frente al todavía mayoritario predominio del consumo de sol y playa, juega un papel cada vez mayor la historia de los hombres, el conocimiento y el disfrute de las obras de la Humanidad a través de todos los tiempos.

Unas obras que reflejan con fidelidad la realidad social de cada conjunto humano y, más aún, la personalidad espiritual y material, mezcla de ideas y de artefactos, de cada sociedad. Realidad y personalidad visibles en el complejo de edificios y muebles varios, es decir, en el patrimonio monumental e histórico fruto palpitante de las necesidades y los anhelos de todos los pueblos y, también, de la acción y la actitud de sus minorías más significadas y distinguidas. Edificios y muebles que reflejan, en fin, la personalidad histórico-artística de cada grupo humano y constituyen la identidad cultural de cada pueblo.

Un patrimonio monumental -cultural en definitiva- que, sin olvido de la originalidad propia de cada caso, es el resultado de la presencia y las actividades de los Hombres durante muchos milenios y de cuántas gentes y culturas a menudo muy contrastadas conforman la Humanidad. Y que por ello ofrece una cierta unidad, al ser consecuencia de la acción y el comportamiento globales de la especie humana, mereciendo así la calificación de Patrimonio de la Humanidad y tendiendo a identificarse en el hecho indudable de unos casos -monumentos, bienes- excepcionales por su pasado, por su belleza y por su originalidad en lo que ha venido en llamarse Bienes Patrimonio de la Humanidad.

Así ha venido a concretarse un planteamiento teórico con raíces materiales hecho realidad institucional el 16 de noviembre de 1972 con la aprobación de la Convención para la protección del Patrimonio Mundial Cultural y Natural por la Organización de las Naciones Unidas para la Educación, la Ciencia y la Cultura (UNESCO). Con tal proclamación puede afirmarse que se llevó a efecto un capítulo más, uno de los primordiales en nuestra 
historia reciente, de la "globalización" institucional a que está siendo sometida la Humanidad, pero que no excluye, sino todo lo contrario, la compleja diversidad -a menudo, individualidad o excepcionalidad- del Patrimonio (Global) de la Humanidad.

La institucionalición conceptual del Patrimonio de la Humanidad es, por tanto, muy reciente. Pero el nacimiento de lo que significa como preocupación teórica y/o práctica viene muy de lejos. Incluso, como leyenda o mito. Ya en el siglo II antes de Jesucristo, Antipater de Sidón se refiere a las llamadas en la Antigüedad "Siete Maravillas del Mundo", aquellos monumentos semilegendarios -y en su mayoría ya desaparecidos- que fueron las Pirámides de Egipto, los Jardines Colgantes de Babilonia, la Estatua Criselefantina de Zeus -obra de Fidias- en Olimpia, el templo de Artemisa en Éfeso, el Mausoleo de Halicarnaso, el Coloso de Rodas y el Faro de Antioquía. Se manifestó ya entonces una idea de excepcionalidad evidente que subsistió en el tiempo y en el recuerdo de los hombres y permitió, en ciertos momentos, añadir nuevos nombres a la lista. Así ocurrió con El Escorial hispano, la "Octava Maravilla del Mundo" para algunos autores.

El reconocimiento de estas excepcionalidades, mantenida a lo largo de siglos y repetida hasta la saciedad en todo Occidente, justificó siempre -y sobre todo en los últimos siglos- determinadas preocupaciones conservacionistas. Fue, por ejemplo, origen de la decisión, en 1960, de salvar las maravillas monumentales existentes a lo largo del valle del Nilo de las aguas del ya en construcción embalse de Assuan y, en especial, del Valle de los Muertos cerca de la antigua Tebas egipcia. El llamamiento a la solidaridad científica internacional hecho por el entonces Director de la Unesco, René Maheu, tuvo pleno éxito, conservándose así un auténtico tesoro, una parte esencial del Patrimonio de la Humanidad (IÑIGO Y ARADILLAS, 1994).

Desde entonces, la UNESCO se ha convertido en paladín de la defensa y salvaguardia de las obras más representativas de la Humanidad. Pero no sólo de este patrimonio histórico y monumental, de estos Bienes Culturales. Muy pronto, la idea se extendió al Medio Ambiente y así la Conferencia de las Naciones Unidas sobre el Medio Humano celebrada en 1972 en Estocolmo confirmó y amplio la idea que condujo ese mismo año a la ya citada Convención para la Protección del Patrimonio Mundial Cultural y Natural aprobado por la ONU el 16 de Noviembre de 1972 como fruto final de las reuniones de la UNESCo celebradas en París entre el 17 de octubre y el 21 de noviembre de 1972. Una convención rápidamente difundida y pronto aceptada por todo el mundo, aunque su vigencia oficial sólo tuvo lugar tres años más tarde, en 1975.

La Convención, que ha sido aceptada y firmada por un total de 150 países, funciona bajo la dirección de un Comité Intergubernamental denominado Comité del Patrimonio Mundial y que está constituido por representantes de 21 Estados firmantes de la Convención elegidos entre la totalidad de los que la componen. Su mandato tiene una duración de seis años que se renueva por tercios al final de cada Conferencia General de la Unesco. Ade- 
más existen los Comités nacionales que atienden y cuidan del buen funcionamiento de la Convención en cada uno de los Estados firmantes. Por lo general, la representación de cada Estado está constituida por personalidades especializadas en la conservación del patrimonio cultural y natural.

El Comité del Patrimonio Mundial se reúne normalmente una vez al año y tiene como principales atribuciones:

a) Identificar y proponer aquellos lugares de interés natural y cultural que deben ser protegidos por la Convención del Patrimonio Mundial, inscribiéndolos en la Lista del Patrimonio Mundial,

b) Difundir por todo el mundo la existencia de este Patrimonio y procurar despertar en la opinión pública la conciencia de su responsabilidad respecto a la salvaguardia de cada uno de los Bienes inscritos,

y c) Proporcionar ayuda técnica con cargo al Fondo del Patrimonio Mundial para la preservación de aquellos Bienes propios de Estados cuyos recursos y posibilidades técnicas son insuficientes.

El cumplimiento de estas funciones se hace posible gracias a la existencia del Fondo del Patrimonio Mundial constituido por las contribuciones -unas obligatorias, otras voluntarias- de los Estados firmantes de la Convención, así como por las aportaciones, donaciones y legados que puedan hacer otros Estados, las diversas organizaciones mundiales dependientes de la ONU y otros organismos o personas físicas públicos y privados.

En estas tareas el Comité recibe la asistencia, primero del Consejo Internacional de Monumentos y Lugares de Interés Artístico e Histórico (ICO$M O S$ ), nacido en Venecia en 1964 y que, bajo el patrocinio de la UNES$\mathrm{CO}$, ha extendido su acción por todo el mundo a través de sus diferentes Comités Nacionales. Y, en segundo lugar, de la Unión Internacional para la Conservación de la Naturaleza y sus Recursos (VICN), otra organización internacional también apoyada por las Naciones Unidas y constituida en 1972 en Estocolmo.

La designación de un monumento o lugar como bien del Patrimonio Mundial se inicia en cada Estado miembro con la preparación de un expediente y una propuesta que describe y valora las características naturales, monumentales e históricas del hecho, considerado siempre en función de las condiciones requeridas por los Estatutos aprobados por la Convención. Más tarde, la UNESCO, con la colaboración de los organismos oficiales o no gubernamentales (OGN) que considera convenientes, decide entre las propuestas presentadas aquellas que se incorporarán a la Lista de Bienes del Patrimonio Mundial.

Es indudable que los criterios que sirven para definir los bienes naturales y culturales no son siempre los mismos. Su diferencia fundamental se encuentra en el origen esencialmente humano de los culturales, y en la nula o baja presencia del hombre en los naturales. Pero, en todos los casos, es fundamental la excepcionalidad de la obra de la Naturaleza o de la Humanidad. Así, en su artículo primero, la Convención afirma que los Bienes Naturales del Patrimonio Mundial deben ser ejemplos excepcionales que representen las etapas principales de la evolución de nuestro Planeta. Y 
hace referencia concreta a procesos geológicos como el glaciarismo o el vulcanismo, a biomas como los bosques de lluvias tropicales, los desiertos y las tundras. Aunque también admite ejemplos de la interacción entre el hombre y su medio natural, como los paisajes de terrazas agrícolas.

Por su parte, los bienes culturales -monumentos individuales, complejos arquitectónicos, lugares o conjuntos- deben constituir un logro artístico único o ser una obra maestra del genio creador y haber ejercido una influencia considerable durante un período determinado de la Historia o en una concreta área cultural del mundo. Aparte, hay que incluir aquellas obras que fueron -o son- testimonio único $\mathrm{o}$, al menos, excepcional de una civilización desaparecida. Por ejemplo, los restos de las sociedades prehispánicas: Teotihuacán, Machu Pichu.

En el momento actual, la última Lista de Bienes Patrimonio de la $\mathrm{Hu}-$ manidad, redactada en 1994, contiene un total de 411 bienes, de los cuales 90 son naturales, 305 culturales y 16 mixtos, distribuidos por 95 Estados del total de firmantes de la Convención. Las mayores concentraciones se encuentran en Europa, con 156 inscripciones, donde Francia y España tienen el mayor número de bienes, 20 cada una, seguidas por el Reino Unido y Alemania, 14 en cada caso, Grecia (12), Bulgaria (9) e Italia (7). A distancia aparecen Asia, con 110 bienes inscritos, y dos núcleos básicos, India/Srilanka, con 26, y China, con 10, y América, con 76 inscripciones, bastante dispersos, Estados Unidos y Canadá, con 25, México, con 13, Perú, con 8, Brasil, con 7, Argentina, con 4, y Bolivia, con 3. Por su parte, en el continente africano existen 58 bienes inscritos, destacándose Etiopía y Argelia, con 7 cada uno, Túnez, con 6, y Egipto, con 5. Finalmente, Australia cuenta con 9 bienes y Nueva Zelanda, con 2. En esta última parte del mundo dominan absolutamente los espacios naturales, ya que la totalidad de los bienes existentes tienen ese carácter. Y son también numerosos los Bienes naturales en América, 36 de los 76 inscritos, y en Africa, 21 sobre 58, siendo contraria la relación existente en Europa, sólo 6 bienes naturales frente a 150, y Asia (11 y 99).

Entre los Bienes culturales se destacan los que el apartado segundo del Artículo $1^{\circ}$ de la Convención denomina "conjuntos" en contraposición a los "monumentos y a los "lugares", es decir los "grupos de construcciones, aisladas o reunidas, cuya arquitectura, unidad e integración en el paisaje les da un valor universal excepcional desde el punto de vista de la historia del arte o de la ciencia". Se trata, en gran medida, de las ciudades ó cascos urbanos históricos de los que, en la Lista del Patrimonio Mundial de 1994 se incluyen un total de 97 , con ejemplos tan paradigmáticos como las europeas Cracovia, Dubrovnik, Toledo, San Petersburgo o Venecia, las americanas Cartagena de Indias, Cuzco, Ouro Preto, Potosí o San Juan de Puerto Rico, las asiáticas Damasco, Estambul, Jerusalán o Petra, o, finalmente, las africanas El Cairo, Kairuan, Marraquech y Timbuctú.

En 1991, los responsables de las setenta ciudades que se integraban entonces en la Lista decidieron en el Coloquio Internacional de las Ciudades Patrimonio de la Humanidad reunido en Québec formar una Federación 
Mundial. En la Declaración sobre la Protección de los Conjuntos Históricos Urbanos en aquel momento proclamada, decidieron tal constitución con el objetivo básico de superar el "agudo problema" que "constituye la conservación del patrimonio urbano" distribuido por todo el mundo y procurar su gestión eficiente y solidaria. Para ello, bajo los auspicios de la UNESCO y la colaboración del ICOMOS se aprobó en Québec la organización de una Red de Ciudades del Patrimonio Mundial, cuya función sería "suscitar, mantener y desarrollar la cooperación y el intercambio de información no sólo entre las ciudades miembro, sino también con el resto de las ciudades históricas de todo el mundo". La Asamblea General constitutiva de la Red tuvo lugar en Fez el 8 de septiembre de 1993, aprobándose entonces sus Estatutos. En esa Red mundial existen, diferenciados por Estados pero ligados entre sí, Grupos de Ciudades Patrimonio de la Humanidad; por ejemplo el español, formado por un total de seis urbes -Avila, Cáceres, Salamanca, Santiago de Compostela, Segovia y Toledo-, un hecho que hace de España uno de los países con mayor número de ciudades con tal título. El Grupo español se formalizó en Avila en una reunión celebrada el 17 de septiembre de 1993.

En la tarea que se impuso la Red de Ciudades del Patrimonio Mundial colabora muy eficazmente ICOMOS a través de una serie de acciones presididas por la Carta Internacional para la Conservación de las Ciudades Históricas, un documento elaborado muy cuidadosa y lentamente por el mismo ICOMOS a partir de la Carta de Venecia de 1964 y objeto de añadidos y modificaciones en sucesivas reuniones habidas en Brujas (1975), Verona (1985) y Toledo (1986), lugar y momento en que fue aprobada.

Todo ello prueba la importancia y significación global e individual del Patrimonio Cultural de la Tierra. Pero también el problema evidente de su implicación en el desarrollo del ocio y el turismo mundiales y, más aún, en los intereses económicos cada vez más poderosos y "globalizadores" de las actividades económicas derivadas. Es indudable, en principio, que la creación del fondo mundial cultural y natural sólo tuvo en su origen un objetivo, la conservación y salvación de aquellas partes de la Tierra excepcionales por su belleza, su calidad natural o histórica y su originalidad. Así, por ejemplo, se excluyeron determinados "bienes" muy significados a causa de su avanzado deterioro, casi siempre motivado por el crecimiento demográfico y/o económico más o menos especulativo a que han estado sometidos últimamente los lugares o conjuntos urbanos de los que forman parte.

Pero, en cambio, la Convención se apresuró a intervenir con todos los medios a su alcance en otros casos, como Pera, el barrio de Estambul, o el conjunto monumental de Angkor (Camboya), para defender y salvar realidades monumentales e históricas de gran valor y en evidente peligro de destrucción parcial o total. Incluso, la declaración de Bien del Patrimonio Mundial impone condiciones muy estrictas, tanto públicas como privadas, a la comunidad humana relacionada con ese Bien y dirigidas a su salvaguardia y recuperación. Llegando hasta el extremo de plantear la posibilidad de retirar la inscripción en la Lista si el Estado correspondiente no se esfuerza 
en atenerse al máximo a las exigencias conservacionistas del Comité del Patrimonio Mundial. Aunque en todos los casos las ayudas, a menudo fundamentales, del mismo Comité para la inscripción y salvaguardia de tales Bienes juegan siempre un papel esencial en el establecimiento y mantenimiento del conjunto del Patrimonio de la Humanidad.

Como contrapartida, no es menos evidente que, en casi todos los casos, los grupos públicos o privados interesados en el nombramiento tienen como uno de sus principales objetivos el desarrollo "in situ" de la actividad turística. En primer lugar, la "imagen" derivada de la calificación de Bien Patrimonio de la Humanidad puede convertirse fácilmente en un excelente "slogan" publicitario. Y, en todo caso, la atención, material o no, recibida por el monumentos, el conjunto urbano o el espacio natural gracias a esa designación favorece no sólo la vitalidad de tales bienes sino que, lo que es más importante, mejora la calidad del recurso turístico y facilita la atracción del viajero hacia él y, en definitiva, el crecimiento de los ingresos económicos generales y particulares derivados del desarrollo turístico.

Es claro que, a la vez, el aumento de visitantes origina una fuerte "presión" ambiental que, casi siempre, provoca un cambio profundo en la vida social y en la misma manera de ver los hechos y los problemas por parte de la sociedad local. Y puede crear a veces una compleja y no siempre fácil coexistencia entre el residente y el visitante, lógica sobre todo cuando la distancia cultural que los separe sea considerable. Además, la atención adecuada a una masa creciente de turistas, a menudo con exigencias vitales muy distantes de las existentes en el lugar visitado, precisa de una infraestructura tanto humana como material costosa y difícil y que, además, puede afectar al mismo recurso turístico llegando a amenazar su misma existencia o, al menos, su integridad histórica y/o monumental.

En todos los casos, el ambiente material o vital de un bien concreto, aunque no se vea afectado formalmente, siempre sufre un cierto deterioro en su ambiente vital y social. Un deterioro que se inicia con la mera presencia física del turismo de masas, con sus grandes grupos de visitantes, tan característicos -e imprescindibles?- de la actividad turística actual. O que puede presentarse por la necesidad de permitir un acceso fácil al monumento o el paisaje, motivando la reestructuración y/o readaptación de los medios de transporte o provocando la aparición artificial y destructora del aparcamiento individual o colectivo.

Y que, en fin, puede transformar la misma imagen, ambiental o social, del bien turístico devaluando su valor intrínseco y su inmediato interés. Algo que también tiene lugar con el desarrollo imprescindible de la hostelería, principal utillaje del crecimiento turístico y cuyas grandes construcciones pueden llegar a afectar a los mismos bienes a los que tratan de servir. Los problemas del urbanismo moderno, por ejemplo, la dicotomía remodelación-rehabilitación de las ciudades, sobre todo las de añeja historia, es su consecuencia inmediata y uno de los puntos de partida de la complejidad de la vida contemporánea en las ciudades.

Así, podría llegarse a establecer la incompatibilidad entre el Turismo y el 
Patrimonio de la Humanidad, tanto cultural como natural. Algo que, es evidente, no puede aceptarse como principio exclusivo, pero que, por otra parte, no puede obviarse. Y que exige una concienzuda consideración de los problemas de esa dicotomía y la precisión de facilitar su profunda comprensión y la búsqueda imaginativa de soluciones efectivas a la conservación del Patrimonio de la Humanidad y a su uso eficaz pero respetuoso como recurso turístico.

En definitiva, como los mismos Estatutos de la Convención creadora del Patrimonio establecen, es deseable -y necesario- que los espacios naturales no sean meras reliquias ajenas a la vida humana. Y que tampoco los bienes culturales, en concreto los conjuntos urbanos, hoy los hechos más dinámicos de la Humanidad, "lleguen a ser otras tantas ciudades muertas, ni tampoco ciudades cuyos inquilinos sean en exclusiva oficinistas. Lo deseable es que sigan siendo ciudades vivas" (BOSQUE MAUREL, 1994). Y cabría añadir "habitables" o, mejor, "vivibles" para todos sus habitantes sin distinción. Algo que, teniendo en cuenta la creciente "globalización" técnicoeconómico-informativa, con su igualitarismo casi siempre insoportable, exige cada vez más una inteligente preocupación y una cuidadosa vigilancia de la pureza originaria y la imprescindible originalidad del Patrimonio Cultural y Natural de la Humanidad.

\section{BIBLIOGRAFIA.}

AAVV (1989): "Historia urbana i intervenció en el centre històric», III Setmana d'Estudis Urbans a Lleida, 6-10 d'octubre de 1986, Barcelona, Institut Cartogràfic de Catalunya, 385 pags.

AAVV (1994): I Reunión sobre el Patrimonio de la Humanidad, Madrid,

AAVV (1994): «La ciudad accesible», II Congreso sobre movilidad y calidad ambiental, Toledo 19,20 y 21 de octubre, MOPTMA, Ayuntamiento de Toledo, FEMP.

AÑóN, C. (DIR.) (1993): Jardins et Sites Historiques. ICOMOS Journal scientifique, 1, 377 pags.

BERNAL, A.M. Y OTROS (1979): Tourisme et developpement regional en Andalousie, Publications de la Casa de Velázquez, V. París, E. Brocard, 324 pags.

BOSQUE MAUREL, J. (1993-94): «La ciudad habitable. Utopía o realidad», Cuadernos Geográficos de la Universidad de Granada, 22-23, pp. 7-16.

BOSQUE MAUREL, J. (1995): «Reflexiones en torno a los espacios naturales protegidos», Simposio sobre Desarrollo y Naturaleza, Puente Génave (Jaén), Universidad Nacional a Distancia, noviembre de 1994,

CAMPESINO FERNÁNDEZ, A.J. (1986): «Revalorización funcional de los centros históricos españoles», Estudios sobre espacios urbanos, Madrid, Casa de Velázquez y Universidad Complutense.

CAMPESINO FERNÁNDEZ, A.J. (1989): «La rehabilitación integrada de los centros históricos: el reto urbanístico de finales de los ochenta», Investigaciones geográficas, Instituto Universitario de Geografía, Universidad de 
Alicante, 7, pp. 7-17.

CAMPESINO FERNÁNDEZ, A.J. (1989): «Los centros históricos: análisis de su problemática», Norba. Revista de Geografía, Universidad de Extremadura, V, pp. 51-61.

ICOMOS (1987): «Charte Internationale pour la sauvegarde des villes historiques», ICOMOS Information, avril-juin, 2, pp. 1-8.

IÑIGO, J.M ${ }^{\mathrm{a}}$ y ARADIllaS, A. (1994): Guía de las Ciudades Patrimonio de la Humanidad. Avila, Cáceres, Salamanca, Santiago de Compostela, Segovia, Toledo, Madrid, Gaesa, 355 pags.

ROMAN, A. (COMPIL.) (1993): «Ciudades históricas», ICOMOS, Revista Científica, 2, 366 pags.

VAlenzuela Rubio, M. (1988): «Ciudad y calidad de vida. Políticas e instrumentos para la recuperación social del espacio urbano», en VILA VALENTí, J. (Coord.), Espacios rurales y urbanos en áreas industrializadas, II Congreso Mundial Vasco, Vitoria-Gasteiz, septiembre 1987, Barcelona, Oikos Tau, pp. 117-144.

VAlENZuela Rubio, M. (Coord.) (1992): «Geografía del turismo y del ocio», en La Geografía en España (1970-1990), Aportación Española al XXVII $^{\circ}$ Congreso de la Unión Geográfica Internacional, Madrid, RSG, AGE y Fundación BBV, pp. 203-212. 